\title{
Mediterranean spotted fever
}

\section{Thanikai $S^{1}$, Sivansuthan $S^{1}$}

${ }^{1}$ Teaching Hospital, Jaffna,

\section{Background}

Rickettsiosis is an arthropod vector born zoonotic infection (1). It causes acute febrile infection and is a cause of prolonged fever when not treated. It is a reemerging infection in Sri Lanka as well as worldwide due to increased travel and recreational activities. Scrub typhus caused by Orientia tsutsugamushi is the commonest rickettial infection in Sri Lanka but spotted fever group rickettial infections are also documented in some parts of Sri Lanka $(2,3)$. Here we report a case of spotted fever group rickettsiosis presenting with prolonged fever and purpuric rash.

\section{Case report}

A previously healthy 60 years old female presented with high grade fever of 10 days duration associated with severe headache. She also complained of generalized myalgia, loss of appetite and dry cough of same duration. Her urine output was reduced. There is no history of recent travel. She couldn't recall any tick bite in the recent past. She lives in a cemented house, and there is an abandoned land next to them with bushes where street dogs and donkeys are usual habitants.

On examination, she was pale, anicteric and oedema. On day 7 of illness she developed non blanchable purpuric rash on her palms and sole later progressed to involve upper thigh and upper arm. (Figure 1) She did not have an eschar. Apart being drowsy and confused she did not have any other significant clinical finding.

The patient's complete blood count showed total white blood cell (WBC) count of $2.56 \times 10^{9} / \mathrm{L}(37 \%$ neutrophils, 45\% lymphocytes and 25\% monocytes), haemoglobin of $10.8 \mathrm{~g} / \mathrm{dl}$ and her initial platelet count was $326 \times 10^{9} / \mathrm{L}$ which later dropped to $36 \times 10^{9} / \mathrm{L}$. Blood picture showed normochromic normocytic anemia, neutropenia with marked monocytosis. Her coagulation profile was within normal limits. Her serum creatinine was 82 micro$\mathrm{mol} / \mathrm{L}$ with severe hyponatrimia $(118 \mathrm{mmol} / \mathrm{L})$, serum potassium was normal. Her liver enzymes were elevated (AST 100 U/L, ALT 142 U/L, ALP $304 \mathrm{U} / \mathrm{L}$ ). She had marked hypoalbuminaemia (total protein $54 \mathrm{~g} / \mathrm{L}$, albumin $18 \mathrm{~g} / \mathrm{L}$ ). Her ESR was $12 \mathrm{~mm} / 1^{\text {st }}$ hour and initial CRP was $127 \mathrm{mg} / \mathrm{L}$. Her blood and urine cultures were sterile. Her transthoracic echocardiogram was normal except for a thin rim of pericardial effusion. Immuno flouresence assay for Rickettsia conorii IgG titer was strongly positive $(>1: 256)$.

Our patient was treated with oral doxycycline, in addition to intravenous ceftriaxone started in local hospital. She was afebrile after 3 days of doxycyclin. Her hyponatrimia slowly corrected with $3 \%$ saline. She recovered completely, and her rash regressed during follow up.

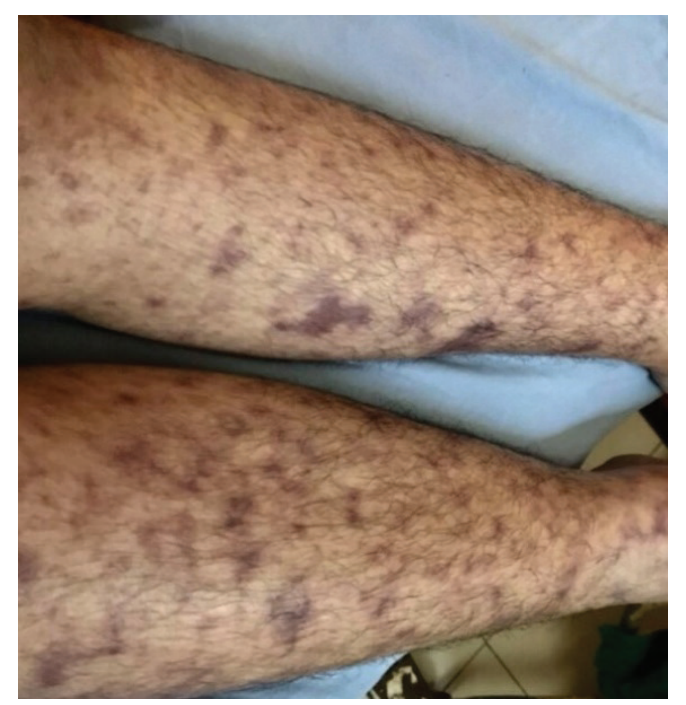




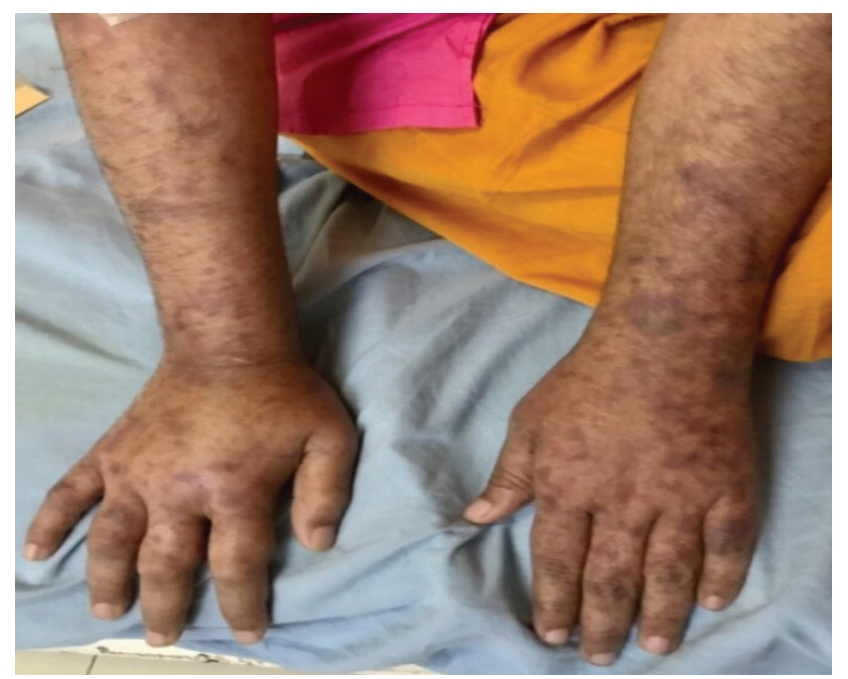

Figure 1: Purpuric rash of Mediterranean spotted fever

\section{Discussion}

Mediteranean spotted fever also known as Boutonneuse fever is transmitted by the dog tick Rhipicephalus sanguineus. Patients develop an eschar at the site of tick bite. The aetiological agent is Rickettia conorri, which is endemic in Mediterranean basin also prevalent in Sourthern Europe, Africa and central Asia. Incubation period is usually 4 to 15 days. Infection caused by R.conorri is usually mild but severe infection with multi organ involvement also seen in about $10 \%$ patients; still mortality rate is about $2-5 \%$.(4)

High spike fever of 39-41 C, headache, myalgia and arthralgia are the commonly reported clinical features. Non-pruritic skin rash, mainly on lower legs occurs 2-6 days after the onset of fever. As in other Rickettsiosis, R.conorri infection also causes Leucopenia, lymphopenia and thrombocytopenia. Lliver enzymes alteration is seen in $60 \%$ patients.

The malignant form of the disease is diagnosed based on combination of clinical symptoms and laboratory findings. Presence of two or more of the following clinical features indicate malignant Mediteranean spotted fever; they are purpuric rash, stupor, bradycardia, jaundice, GIT bleeding, arthritis, local lymphadenopathy, hepatospleenomegVol.32, No.2, Nove 2020 aly, orchitis and meningism. Thrombocytopenia $(<100 \times 109 / \mathrm{L})$, elevated serum creatinine, hyponatremia $(<130 \mathrm{mmol} / \mathrm{L})$, hypoxia and hypocalcemia also indicate severe disease.

Both culture and serology can be used to confirm diagnosis. The antibody titer in serum is increased only two weeks after the infection, reaches its peak level after 4 weeks and remains elevated for several months. Immnofluorescence is considered positive when there is a fourfold rise in antibody titre, single antibody titre in $\operatorname{IgG} \geq 1 / 128$ or an $\operatorname{IgM}$ titre $\geq 64$. $(5,6)$

Oral doxycyclin is the drug of choice, intra venous chloramphenicol can be considered in malignant form. Single dose of Azithromycin can be used for prophylaxis.

\section{Conclusion}

Mediteranean spotted fever is an emerging infection in Sri Lanka, should be considered in all patients with febrile illness. Due to the wide range of clinical presentation and limited serological tests this infection is under diagnosed or may be misdiagnosed as scrub typhus. Doing serological investigations to find out the species of Rickettiae in all patients with suspected Rickettial infection will help us to find out the prevailing species in our part of Sri Lanka and appropriate preventive measures can be taken.

\section{References}

1. Praveen K, Michael C. Rickettsial diseases; Kumar \& Clark's Clinical Medicine.

2. Kularatne SA, Edirisingha JS, Gawarammana IB, Urakami H, Chenchittikul M, et al. Emerging rickettsial infections in Sri Lank: the pattern in the hilly Central Province. Tropical Med Int Health. 2003;8(6):803-11

3. Kularatne SAM, Rajapakse RPVJ, Wickramasinghe WMRS, Nanayakkara DM, Budago- 
da SS, et al. Rickettsiosis in the central hills of Sri Lanka; serological evidence of increasing burden of spotted fever group. Int J Infect Dis. 2013;17(11):e988-92

4. Elena E, Andra M, Garcia MC, Fajardo A, Mauri M, Perez J, Bella F, et al. Mediterranean Spotted Fever in the Elderly: A Prospective Cohort Study. Eur J Clin microbial Infect Dis. 2019 Jul;38(7):1333-1337
5. Broadhurst LE, Kelly DJ, Chan CT, Smoak BL, Brundage JF, McClain JB, et al. Laboratory evaluation of a dot-blot enzyme immunoassay for serologic confirmation of illness due to Rickettsia conorii. Am J Trop Med Hyg. 1998 Jun. 58(6):786-9.

6. Nagalingam K, Rolain JM, Thevanesam V, Lak Kumar F, et al. spotted fever rickettsioses in children in Sri Lanka. European Society of Clinical Microbiology and Infectious Disease. CIM, 15(Suppl.2), 330-331 